\title{
Hermenêutica política: a contribuição de Hannah Arendt à hermenêutica filosófica*
}

\author{
VASTERLING, Veronica. Political hermeneutics: Hannah Arendt's \\ contribution to hermeneutic philosophy. In: WIERCINSKI, A. (Ed.). \\ Gadamer's Hermeneutics and the Art of Conversation. Berlin:Verlag, \\ 2011, p. 571-582.
}

\author{
José Valdir Teixeira Braga Filho (Tradutor) \\ Orcid: https://orcid.org/0000-0003-3606-3655 - E-mail:valdir_bfilho@hotmail.com
}

Uma das consequências da difundida recepção da filosofia pós-estruturalista, particularmente do trabalho Michel Foucault, consiste na consciência crítica da dimensão política da verdade. Apesar de necessária, essa nova consciência também promoveu uma concepção enganosa da verdade que tende a igualar verdade com poder. Essa concepção é enganosa, porque o importante insight de que, de fato, verdade e poder podem estar relacionados de várias maneiras, perde-se em uma generalização superficial que causa mais dano do que benefício à uma compreensão [Verstehen] adequada sobre o que está em jogo. Uma das consequências prejudiciais da convicção de que a verdade é igual ao poder, consiste em desacreditar atos como, meramente, invenções interpretativas que são trajadas como fatos inegáveis por aqueles que estão no poder, como políticos e cientistas. Embora baseado em um insight valioso, neste caso, o reconhecimento de que fato e interpretação são inseparáveis, leva tal insight a se perder novamente no gesto generalizado de desacreditar o valor verdadeiro dos fatos. Isso ocorreu de modo particularmente danoso nos debates sobre fatos políticos e científicos. A convicção de que fatos são invenções interpretativas evita qualquer discussão produtiva sobre a verdade e o sentido dos fatos. Além disso, ela também instala um tipo niilista de relativismo, isto é, um relativismo que rejeita a verdade factual em favor de uma diversidade de perspectivas subjetivas, opiniões, interpretações e similares.

\footnotetext{
"Tradução de Political Hermeneutics: Hannah Arendt's contribution to Hermeneutic Philosophy, de Veronica Vasterling, IN WIERCINSKI, A. (ed.), Gadamer's Hermeneutics and the Art of Conversation. Berlin: Verlag, 2011, p. 571-582. Tradução de José Valdir Teixeira Braga Filho. Revisão de Edinei Soares de Oliveira Junior e Lucas Barreto Dias. Agradecemos à autora por permitir que o seu texto fosse traduzido e por todo apoio para que o projeto fosse concretizado. Além disso, não se pode deixar de notar a contribuição de Odílio Alves Aguiar, que forneceu apontamentos valiosos.
} 
Nessa contribuição, eu quero tratar desses equívocos pervasivos sobre o estatuto da verdade factual. Equívocos que, conforme argumentarei, podem ser esclarecidos com ajuda de uma hermenêutica politicamente sensível. O propósito deste ensaio é apresentar como a obra de Arendt pode ser uma fonte muito útil para elaboração e extensão políticas da hermenêutica gadameriana. Embora quase nunca seja reconhecida, até agora, na vasta recepção de seu trabalho, as raízes filosóficas de Arendt são de fato muito próximas das de Gadamer. Ambos estudaram com Heidegger na década de 1920. Gadamer e Arendt compartilham uma profunda influência da hermenêutica fenomenológica inicial de Heidegger. O mais importante é que ambos transformaram esse legado de uma maneira extremamente produtiva, em uma hermenêutica filosófica, no caso de Gadamer, e numa hermenêutica política, no caso de Arendt. ${ }^{1}$ Conforme argumentei em outra ocasião, a hermenêutica filosófica de Gadamer fornece ferramentas críticas que são indispensáveis para uma hermenêutica política, mas também revela uma flagrante insensibilidade política em alguns aspectos. ${ }^{2}$ Gadamer elabora em Verdade e Método uma concepção hermenêutico -ontológica sobre a situação da compreensão e a pluralidade de sentido com respeito à verdade, à interpretação válida e à possibilidade de compreensão compartilhada. Essa concepção é muito útil para uma hermenêutica política que reconhece, por um lado, a conexão com a verdade e, por outro, uma pluralidade de sentido ou interpretação. Todavia, o potencial crítico da hermenêutica gadameriana é limitado ao menos em dois aspectos. Primeiro, sua noção de pluralidade é insuficiente porque é circunscrita e superada pela unidade de acordo ou pela fusão de horizontes. Segundo, não há reflexão sobre a paradoxal relação entre verdade e sentido. A concepção consensual da pluralidade é implicada pela insistência de Gadamer de que a compreensão verdadeira envolve acordo ou fusão de horizontes. Compreensão verdadeira não envolve "a empatia de um indivíduo por outro nem subordina uma outra pessoa aos nossos próprios padrões; em vez disso, ela sempre envolve ascender a uma universalidade superior que supera não apenas nossa própria particularidade, mas também a do outro"3. Para Arendt, a compreensão verdadeira também pressupõe a superação da própria particularidade, mas, ao contrário de Gadamer, ela pode ser superada apenas pela ampliação de uma perspectiva com outras e de tal modo alcança uma compreensão genuinamente pluralista, mais representativa e menos parcialmente compreensiva. Conforme explicarei no curso deste ensaio, esse exercício não exige fusão de horizontes, consenso ou perspectivas compartilhadas. Arendt é também a única filósofa hermeneuta que conheço que elucida a relação paradoxal entre sentido e verdade de um modo que auxilia a desembaraçar os equívocos pervasivos sobre o estatuto da verdade e, em particular, o valor de verdade dos fatos. Sua hermenêutica dos fatos apresenta como a rejeição do

\footnotetext{
1 A influência de Heidegger no pensamento de Arendt é geralmente reconhecida. O que dificilmente se reconhece é que a hermenêutica e a fenomenologia são as partes mais importantes do seu legado. Ver, TAMINIAUX, Jacques. La fille de Thrace et le penseur professional: Arendt et Heidegger. Paris: Éditions Payot, 1992; BENHABIB, Seyla. The Reluctant Modernism of Hannah Arendt. London: Sage, 1996. Para exceções desta regra ver BORREN, Marieke. Amor Mundi: Hannah Arendt's political phenomenology of world (http://dare.uva.nl/record/346972).

2 O sinal mais óbvio da cegueira política de Gadamer é a sua noção de tradição. Seu retrato da tradição como "o grande tapete que nos suporta". GADAMER, Hans-Georg. Truth and Method, 2a ed. Trans.JoelWeinsheimereDonald G. Marshall.NewYork:Continuum, 1999, p. 338. Negligencia completamente o papel que as lutas de poder exercem na tecelagem deste tapete. Nenhum estudante de história pode ignorar o fato que a tecelagem dos tapetes da tradição envolve lutas contínuas e algumas vezes mortais em que livros são queimados e pessoas são silenciadas. Em vista das lutas de poder envolvidas, a tradição não pode simplesmente ser igualada à autoridade, assim como pensa Gadamer (ibidem, p, 280). A tradição também é a história dos vencedores, uma história que ganha autoridade porque a memória dos dissidentes, dos silenciados, dos perdedores é esquecida e apagada. Ver aqui para mais discussão VASTERLING, Veronica. Postmodern Hermeneutics? Toward a Critical Hermeneutics. In: CODE, Lorraine. Feminist Interpretations of Hans-Georg Gadamer. University Park: Pennsylvania State University Press, 2003, pp. 149-180. Também CAPUTO, John D. Radical Hermeneutics. Repetition, Deconstruction, and the Hermeneutic Project. Bloomington: Indiana University Press, 1987.

${ }^{3}$ Gadamer. Truth and Method. p. 305.
} 
valor de verdade dos fatos destrói a conexão crucial entre interpretações plurais e a realidade factual, minando assim nosso senso de realidade.

Talvez mais do que a própria obra de Gadamer, a obra de Arendt é exemplar quanto a um importante aspecto da hermenêutica gadameriana, bastante enfatizado por ele, a saber, que a hermenêutica não é um sistema teorético, mas uma práxis reflexiva. A maioria dos trabalhos de Arendt, por exemplo, seus livros sobre o totalitarismo ${ }^{4}$ e seu livro sobre Eichmann ${ }^{5}$, para citar dois exemplos óbvios, consistem no esforço de atingir uma compreensão melhor dos fenômenos mundanos que são de vital importância no mundo político contemporâneo. ${ }^{6} \mathrm{Em}$ Arendt, "Politico" refere-se a certo tipo de ação, não apenas ao conteúdo, portanto, incluindo discurso, isto é, ação e discussão em que perspectivas plurais estão explicitamente em jogo. Discussões pluralistas são típicas do mundo contemporâneo numa larga abrangência de tópicos, quer sejam sobre fatos científicos (evolução), convicções morais ou religiosas (a sacralidade da vida humana) ou problemas políticos no sentido mais simples do termo (a universalidade dos direitos humanos). Entretanto, ao longo da década passada, a discussão pluralista foi minada por duas tendências independentes. Por um lado, está esvaziada pelas consequências destrutivas do descrédito do valor de verdade dos fatos. Por outro lado, a reação negativa que este relativismo niilista tem dado origem consiste em fundamentalismos de diversos tipos. O que fundamentalistas compartilham (seja religioso, político, moral ou científico) é a crença inabalável na verdade absoluta do seu credo particular. A sútil hermenêutica dos fatos de Hannah Arendt não só lança luz nestas consequências alarmantes destas tendências, como também auxilia a desembaraçar os equívocos que indiquei no início desse ensaio.

\section{Antropologia hermenêutica e política}

A fim de preparar o cenário para a discussão da hermenêutica dos fatos de Arendt, eu preciso, primeiro, fornecer alguns bastidores e o contexto. Por que denomino o trabalho de Arendt como uma hermenêutica política e o que justifica esta caracterização?

Arendt é uma pensadora política cuja concepção de política é incorporada a uma ampla visão da "condição humana", não é por acaso que este é o título de uma de suas maiores obras sobre política. ${ }^{7}$ A maioria da literatura sobre Arendt negligencia que a sua concepção de política é parte de uma antropologia filosófica claramente inspirada pela fenomenologia hermenêutica. Na concepção de Arendt da condição humana, compreensão [Verstehen] e narrar estórias [story-telling ${ }_{,}^{8}$ conforme ela denomina, exercem um papel decisivo. Por meio de uma discussão de alguns dos seus termos chave, a saber, mundo, contingência, natalidade e compreensão, espero mostrar por que de fato se pode falar de uma antropologia hermenêutica e política.

Mundo é o que distingue os humanos dos animais, apesar de ser uma distinção gradual em vez de essencial. A vida humana é mundana mais que natural. Enquanto a terra é o habitat natural da espécie humana, provendo-a com oxigênio, água e nutrientes, os seres-humanos habitam, primeira e principalmente, um mundo significativo, um artifício de seu próprio esforço. A distinção de Arendt entre natureza e mundo possui implicações metodológicas que

\footnotetext{
4 ARENDT, Hannah. The Origins of Totalitarianism. New York: Harcourt, 1951.

${ }^{5}$ ARENDT, Hannah. Eichmann in Jerusalem: A Report on the Banality of Evil. New York: Viking Press, 1963.

6 Arendt enfatizou em uma famosa entrevista para a televisão alemã em 1964, publicada em ARENDT, Hannah. Essays in Understanding 1930-1954. Ed. Jerome Kohn. New York: Harcourt, 1994. pp. 1-23. Ver também ARENDT, Hannah. Ich will verstehen: Selbstauskünfte zu Leben und Werk. Ed. Ursula Lutz München: Piper, 1996.

7 ARENDT, Hannah. The Human Condition. Chicago: University of Chicago Press, 1958.

8 Conforme a revisão de Adriano Correia na tradução brasileira d'A Condição Humana. Ver ARENDT, Hannah. A Condição Humana. Tradução de Roberto Raposo. Revisão de Adriano Correia. Rio de Janeiro: Forense Universitária, 2016, 13a ed. (Nota do tradutor).
} 
são reminiscentes do modo pelo qual a filosofia hermenêutica, desde Dilthey, distingue entre a abordagem explicativa das ciências e a abordagem interpretativa das humanidades. Em contraste com as práticas, eventos, ações e estados de coisas que constituem o mundo humano, os fenômenos da natureza não são inerentemente significativos. Examinados da perspectiva do observador desengajado, os fenômenos da natureza permitem explicação causal e conhecimento objetivo. As ciências sociais e comportamentais obtêm conhecimento de maneira similar, acumulando fatos estatísticos e imagens sobre o comportamento e o mundo humano. Arendt critica o reducionismo da abordagem científica, incapaz de capturar a característica constitutiva da ação, do mundo e da história humanas, isto é, sua significação [meaningfulness]. O sentido é intersubjetivo e dependente de contexto em vez de ser objetivo e generalizável. $O$ acesso ao sentido dos eventos, ações e estados de coisas requer a perspectiva de um espectador engajado e endereçável que busca compreender em vez de apenas observar. De modo similar, explicações causais negligenciam e podem falsear a irredutível particularidade e contingência dos fatos e eventos mundanos, bem como a significação das ações humanas. ${ }^{9}$ Contra condições generalizáveis e padrões repetitivos requeridos por explicações causais, Arendt insiste na particularidade da imprevisível novidade dos eventos que compõem o mundo histórico humano. É uma ilusão pensar que podemos explicar e prever revoluções assim como se pode explicar e prever tempestades.

Ao tomar o mundo e a mundaneidade como a característica central de sua antropologia, Arendt é claramente influenciada por Ser e Tempo de Heidegger. Entretanto, pode ser desorientador sugerir que Heidegger e Arendt compartilham o mesmo fundamento substancial na abordagem da mundaneidade da existência humana. Enquanto a abordagem de Heidegger é fielmente ontológica, Arendt é principalmente interessada no mundo como condição necessária da política que, por sua vez, repousa em noções que não estão presentes em Heidegger, isto é, a natalidade e a contingência.

Como um constructo humano, o mundo precisa ser construído e mantido, não apenas no que se refere sua infraestrutura material, mas, também, e especialmente, à sua dimensão imaterial de significância. Arendt descreve esta última como a dimensão dos "assuntos humanos" e eventos e estados de coisas proporcionados pelas ações humanas. ${ }^{10} \mathrm{~A}$ dimensão imaterial da significação precisa de cuidado especial por duas razões. Primeiro, ela consiste em eventos-fenômenos efêmeros, atos e estado de coisas que sobrevivem apenas em palavras ou, de modo geral, em registros de qualquer tipo. Em si mesmos, tais fenômenos não possuem substância e permanência. Se não são registrados nos vários tipos de estórias (da historiografia oficial até romances, incluindo filmes, documentários, opiniões individuais e julgamentos, bem como debates públicos e processos de decisão coletiva) eles desapareceriam, frequentemente sem deixar rastro. Em segundo lugar, o mundo imaterial é extremamente frágil e necessita de um cuidado especial por causa de sua total contingência. Em Arendt, contingência não tem a conotação tradicional de oposição à necessidade. ${ }^{11}$ Preferencialmente, a contingência refere-se a possibilidade do novo. Ao compreender contingência inicialmente habilitando a possibili-

\footnotetext{
${ }_{9}$ Um exemplo recente é a discutidíssima alegação neurocientífica, baseada nos experimentos de Libet, que o livre-arbítrio não existe. Embora exista muita discussão sobre a configuração dos experimentos e da interpretação da informação, o elefante na sala dificilmente chama qualquer atenção, a saber, de que maneira as descobertas neurocientíficas entendem a volição como uma atividade humana significativa. A questão não é se a volição é causada pela atividade neural no cérebro (isto é claro de certo modo), mas o que aqui significa "causa". Séculos atrás quando se descobriu que a terra gira em torno do sol e não o contrário, seres humanos continuaram percebendo o sol circundando a terra por causa do modo em que somos inseridos e incorporados no nosso ambiente terrestre. É uma questão aberta se e como explicações neurocientíficas afetarão a experiência humana da volição e outras atividades. Mas é muito questionável que a ressurreição do determinismo do século XIX seja uma das respostas.

10 lbidem, p. 181-192.

${ }^{11}$ ARENDT, Hannah. The Life of the Mind. Vol. I. Thinking. New York: Harcourt, 1971, p. 60.
} 
dade do novo, Arendt apresenta uma verdadeira nova perspectiva na antropologia filosófica e hermenêutica. Em Arendt, a contingência dos eventos, atos e estados de coisas não se refere apenas ao fato de que eles não têm nenhuma necessidade de ocorrer, nem no modo como eles ocorreram. A contingência dos eventos, atos e estados de coisas significa, sobretudo, que eles podem ser novos ou introduzir algo novo no mundo.

De acordo com Arendt, a contingência, no sentido da novidade, é específica da condição humana. Como toda vida orgânica, a vida humana é restrita pela vida e a morte, natalidade e mortalidade. Contudo, a natalidade nos seres humanos significa mais que o resultado contingente da reprodução sexual - que se pode conceber de uma perspectiva evolucionária naturalista. A natalidade humana significa um novo começo no mundo. Com uma nova vida, algo novo é trazido ao mundo. Novas gerações sempre mudam a face do mundo por causa da capacidade de agir. Arendt conecta natalidade e ação, isto é, com a essência da política, assim como ela compreende. Ação é "agir juntos e aparecer em público (...) inserindo-nos no mundo pela palavra e ato, portanto adquirindo e sustentando nossa identidade pessoal e começando algo inteiramente novo". ${ }^{12}$ Portanto, ação não é apenas a realização da liberdade e pluralidade, é também atividade que pode proporcionar novos eventos e estados de coisas. Na medida em que transcende as intenções, metas e objetivos de atores individuais, a interação pluralista pode resultar em novos eventos ou situações imprevisíveis. Conforme Arendt, a ação não é redutível a meios e propósitos instrumentais ou estratégicos. Os propósitos podem ser, e frequentemente são, parte da ação, entretanto, apenas quando ela é mais que isso, isto é, a realização da pluralidade e liberdade, é que é verdadeiramente ação no sentido de Arendt. Portanto, deve ser claramente distinguida da concepção e da prática política como criação e implementação de agendas políticas e como lobismo.

Arendt chega à sua noção de ação com base numa análise fenomenológica fragmentada, porém, iluminadora, do que a ação envolve. ${ }^{13}$ Sua análise mostra que a ação é sempre ação em concerto, juntamente com outros. Um único ator não é ator nenhum porque um único ator requer minimamente um espectador que possa contar a estória. Uma ação realizada completamente por conta própria desaparecerá sem deixar rastro no mundo. Ação em concerto implica uma dinâmica da pluralidade, isto é, um entrelaçamento de perspectivas plurais que não pode deixar de ter consequências imprevisíveis. Mesmo quando atores individuais estão comprometidos com os mesmos objetivos e os mesmos meios para alcançar esses objetivos, a inevitável pluralidade de suas perspectivas - decorrentes da contextualidade e da história específicas de cada indivíduo - transcenderá as intenções individuais e vai interferir com o objetivo comum, iniciando uma dinâmica que resulta em novos eventos e estado de coisas imprevisíveis. Obviamente, isso só acontecerá quando atores acompanharem o fluxo e superarem a inclinação utilitária de recorrer à ação instrumental e estratégica num esforço para dominar a situação e controlar as consequências. ${ }^{14} \mathrm{~A}$ política no sentido arendtiano ocorre sempre onde e quando houver pessoas agindo e discursando juntas e iguais, trazendo perspectivas plurais à tona. Igualdade é essencial porque dominação e hierarquia evitam interações plurais e a possibilidade de novos eventos e estados de coisas. Essa é uma das razões pelas quais regimes despóticos e autoritários são tão estagnantes.

No sentido enfático da novidade, a contingência conecta-se com outro tema recorrente na antropologia de Arendt: a fragilidade do mundo imaterial. Os fenômenos do mundo imate-

\footnotetext{
12 ARENDT, Hannah. Between Past and Future: Eight Exercises in Political Thought. New York: Penguin, 1961. p. 263.

${ }^{13}$ ARENDT, Hannah. The Human Condition. p. 175-192.

${ }^{14}$ No capítulo IV da Condição Humana Arendt descreve o surgimento do utilitarismo moderno e o seu impacto na percepção e prática política Ocidental. Ibidem, p. 144-174.
} 
rial (eventos, atos e estados de coisas) não são apenas frágeis porque só sobrevivem se forem registrados de algum modo. Eles também são frágeis por seu caráter contingente e, às vezes, sem precedentes que desafia a compreensão (imediata). Caso não sejam registrados de algum modo, novos eventos e estados de coisas correm o risco real de serem reduzidos e, então, desaparecer no velho e conhecido. Conforme Arendt, "a compreensão é um esforço exigente, pois envolve superar a tentação de "negar o chocante, deduzindo o sem precedentes dos precedentes, ou explicando os fenômenos por meio de analogias e generalidades de tal modo em que o impacto da realidade e o choque da experiência já não é mais sentido."15

Parte e parcela da antropologia de Arendt é uma hermenêutica política dos fatos que testemunha o papel principal da compreensão e dos fatos. A compreensão suporta o fardo crucial de manter a significação do mundo pelo reconhecimento, interpretação e registro dos eventos, atos e estado de coisas, em suma, dos fatos que constroem esse mundo. O que eventos, atos e estados de coisas têm em comum é o seu caráter factual, todos os tipos de fatos são uma parte importante do mundo. Arendt, assim como Heidegger e Gadamer, distingue compreensão preliminar, que é acrítica e também é senso comum, similar ao que o primeiro denomina Vorverständnis, da "compreensão verdadeira" que é reflexiva e explicita. ${ }^{16}$ Diferente de Heidegger e Gadamer, a compreensão arendtiana requer enfaticamente a abertura para o "choque da experiência" e, por isso, reconhece os eventos e estados de coisas novos e, por esse motivo, frequentemente incompreensíveis. $O$ choque da experiência é também o choque da incompreensão. Em Arendt, o choque da experiência e a incompreensão são o ponto de partida exemplar para um processo de compreensão que faz justiça ao caráter novo e contingente dos fenômenos que se busca compreender. Reduzir o novo ao velho e conhecido, justificar o contingente com a ajuda de quadros conceituais que produzem consistência (como ocorre tantas vezes na filosofia, ciência, teoria e historiografia) não se qualifica como compreensão no sentido arendtiano. Embora reduções como essas possam ser necessárias para a produção de conhecimento e explicação científica, em toda a sua obra, desde Origens do totalitarismo (1951) até $A$ vida do espírito (1971), Arendt é inflexível. A compreensão não deve ser confundida com conhecimento, ou explicação, ou outras formas de cognição “Compreensão, diferentemente da informação correta e do conhecimento científico, é um processo complexo que nunca gera resultados inequívocos. É uma atividade interminável pela qual, em constante mudança e variação, chegamos a um acordo e nos reconciliamos com a realidade, isto é, tentamos estar em casa no mundo." ${ }^{17}$ Em comparação com as várias formas de cognição, a compreensão é mais capacitada a fazer justiça ao caráter contingente fundamental e, às vezes, verdadeiramente novo, do mundo e dos fatos em particular. Conforme dito anteriormente, a compreensão é mais adequada para fazer isto porque ela tem em vista o sentido, em vez de explicação ou informação. Óbvio que a compreensão depende inteiramente da cognição (sem cognição não há compreensão) contudo, assim como a ação, não pode e não deve ser reduzida à cognição. ${ }^{18} \mathrm{~A}$ questão cognitiva sobre se algo existe e por que existe não pode ser reduzida ou assimilada com a questão "o que significa, para isto, ser" que é a questão da compreensão reflexiva. ${ }^{19}$ Esse problema é importante para Arendt porque a confusão entre compreensão e cognição, ou em

\footnotetext{
${ }^{15}$ ARENDT, Hannah. The Origins of Totalitarianism. p. viii.

${ }^{16}$ ARENDT, Hannah. Essays in Understanding. p. 312.

17 Ibidem, p. 307-308.

18 "Conhecimento e compreensão não são o mesmo, mas eles estão inter-relacionados. A compreensão se baseia no conhecimento e o conhecimento não pode proceder sem uma compreensão preliminar e inarticulada. (...) A compreensão precede e sucede o conhecimento. A compreensão preliminar, a qual é a base do conhecimento, e a verdadeira compreensão, que o transcende, possuem isso em comum: elas tornam o conhecimento significativo. ARENDT, Hannah. Essays in Understanding. p. 310-311.

${ }^{19}$ ARENDT, Hannah. The Life of the Mind. p. 57.
} 
outras palavras, entre sentido e verdade, é perigosa do ponto de vista político. Discutirei a relevância política deste problema na última seção deste ensaio. ${ }^{20}$

\section{Verdade factual e interpretação plural}

O que são fatos? De acordo com Arendt, fatos não são descobertos nem inventados, eles são estabelecidos. Mesmo assim, estabelecer fatos inevitavelmente envolve interpretação. Fatos e interpretação são inseparáveis, entretanto, interpretação, ou como Arendt geralmente denomina, compreensão, deve ser distinguida da invenção assim como da cognição. Compreensão envolve conhecimento e imaginação, mas não pode ser reduzida a eles. É bem comum conhecer e explicar fenômenos sem realmente compreender seu sentido, por exemplo, o começo do universo. Também é bem possível imaginar um fenômeno sem compreender o seu sentido, por exemplo, a morte. Em Arendt, a imaginação é a capacidade de transformar percepção material, experiência e memórias em objetos da reflexão. ${ }^{21}$ Deste modo, imaginação é uma precondição importante da compreensão reflexiva.

Fatos tomados como invenções no sentido foucaultiano não são um produto da imaginação. Fatos são chamados de invenções quando são feitos em vez de encontrados. Mais precisamente, fatos são produzidos por práticas discursivas em vez de descobertos "lá fora". Toma-se, por exemplo, o famoso exemplo atribuído a Foucault de que o homossexual é uma invenção do século XIX.22 Aqui, invenção se refere ao modo como regimes poderosos de conhecimento produzem realidade, ou fatos, neste caso, o fato do homossexual. Assim como outros filósofos pós-estruturalistas, Foucault dá ênfase à mediação discursiva e à produção da realidade. Apesar de não ser insensível quanto a isto, Arendt aborda o mesmo problema por outra direção. Também para Arendt, fatos e, de modo mais geral, a história humana e o mundo são produtos do fazer humano. Mas em contraste com Foucault e muitos outros filósofos, Arendt foca na não intencional e imprevisível novidade dos fatos que sucedem por meio da ação humana. Mais importante ainda, Arendt sublinha o estatuto paradoxal desse tipo de fatos como, simultaneamente, resultado da ação pluralista, mas, mesmo assim, inteiramente contingente e inalterável. A história humana e o mundo humano não são feitos nem dominados, do mesmo modo que fazemos e dominamos o processo de fazer poemas ou tortas de maçã. Em uma extensão significativa, a história e o mundo são - não apenas, mas também - o resultado contingente da ação humana plural, um resultado que nos aconteceu, começando pela natalidade. Cada ser humano nasce num tempo histórico específico e num espaço mundano que é novo e estranho, leva um longo tempo para sentir-se em casa nele, e talvez isso nunca ocorra. ${ }^{23}$

O aspecto mais negligenciado dos fatos a que, entretanto, Arendt nos chama atenção, é a combinação paradoxal de verdade e sentido. Por um lado, fatos são tão verdadeiros como coercivos, imutáveis e unos, por outro lado, permitem uma mutável pluralidade de interpretação. Enquanto a verdadeira dimensão dos fatos parece tornar o debate supérfluo, a dimensão interpretativa exige debate, isto é, por contestação e persuasão. Elucidando a distinção entre

\footnotetext{
20 Para mais discussão sobre o papel da fenomenologia hermenêutica no trabalho de Arendt, ver BORREN, Amor Mundi. capítulo 1 e 2, e VASTERLING, Veronica. Hannah Arendt. In: LUFT, Sebastian. Søren Overgaard (Ed.). Routledge Companion to Phenomenology. London: Routledge, 2011.

${ }^{21}$ ARENDT, Hannah. The Life of the Mind. p. 86.

22 Ver especialmente o segundo capítulo de FOUCAULT, Michel. Histoire de la sexualité. Vol. I - La volonté de savoir. Paris: Gallimard, 1976.

${ }^{23}$ Contudo, pessoas podem sentir e agir como se o mundo lhes fosse próprio, sentir-se em casa no mundo requer de acordo com Arendt, a atividade da compreensão para toda a vida. Porque a história não para e as novas gerações mudam a face do mundo, Arendt sugere que nós nunca nos sentimos completamente em casa no mundo.
} 
verdade e sentido, Arendt enfatiza que se deve resistir à tentação comum de solucionar o paradoxo pela identificação entre sentido e verdade, sujeitando a pluralidade das interpretações à unidade da verdade. ${ }^{24}$ Pelo mesmo motivo, a dimensão verdadeira dos fatos não deve ser reduzida à sua dimensão interpretativa. Em vez disso, deve-se reter os dois lados, porque os fatos não são apenas verdades verificáveis ou tão somente sentido variável, são ambos ao mesmo tempo. Dois exemplos podem iluminar como a verdade factual e interpretação pluralista se associam. A queda do muro de Berlim em novembro de 1989 e a invasão americana no Iraque em março de 2003 são verdades factuais inegáveis e imutáveis. Elas são "uma" e nisso elas não podem ser metade ou um quarto verdade. Alguma coisa é verdadeira ou não. Ainda assim, o sentido - portanto a interpretação ou compreensão - dessas verdades factuais é plural e mudará no tempo. Há e haverão relatos diferentes desses fatos.

O estabelecimento da verdade factual requer compreensão preliminar que depende do senso comum. Em Arendt, senso comum refere-se a ser inserido no mundo permitindo pontos de referência e parâmetros espaciais, temporais e materiais comuns. ${ }^{25}$ Estes pontos de referência comuns permitem-nos estabelecer de modo não ambíguo que a América invadiu o Iraque e não o contrário. A verdade factual é tão coercitiva e inegável como qualquer outra verdade, contudo, não é absoluta, é relativa e contingente. É relativa, no sentido de que a verdade factual só pode ser estabelecida dentro da configuração (framework) de pontos de referência mundanos comuns e é contingente porque a configuração mundana e os eventos nela podem ser de outra maneira ou não ser de modo algum. Mesmo assim, verdade e interpretação não são tão facilmente distinguíveis como os exemplos acima dos chamados fatos concretos. Os fatos concretos são denominados concretos precisamente por causa da possibilidade de distinguir entre verdade factual e interpretações plurais que estas verdades podem significar sem ambiguidade. Por outro lado, muitos fatos são brandos, consequentemente, verdade e sentido não podem ser distinguidos inequivocamente. Nesses casos, o sentido e a verdade do fato permanecem contestáveis.

Estabelecer verdades factuais envolve inevitavelmente atos interpretativos de seleção e nomeação. Arendt descreve a seleção como o ato de destacar um evento discreto, ou uma sequência de eventos, a partir de uma pura confusão sem fim de acontecimentos pelos quais somos continuamente rodeados. ${ }^{26}$ Ver noticiários como CNN ou BBC World é instrutivo a este respeito. A maioria dos novos fatos selecionados para transmissão são invariavelmente aqueles que refletem ou são associados com os interesses, preferências e valores das populações mais poderosas do mundo, que, por enquanto, ainda são aquelas da América do Norte e Europa. Alguns poucos americanos ou europeus mortos tomarão muito tempo da transmissão enquanto os africanos precisam morrer de fome ou ser mortos massivamente para que sejam, enfim, mencionados. Seleção significa que alguns eventos estão em primeiro plano às custas de muitos outros. Os princípios de seleção não são factuais em si mesmos. Eles refletem padrões avaliativos, interesses, dinâmicas de poder, hábitos e preconceitos. Desde o surgimento do mass media e da internet, há uma consciência crescente dos efeitos enfraquecedores e empoderadores da seleção. A seleção pode reforçar estereótipos, interesses manifestos e poderes estabelecidos, mas também pode ser uma estratégia de empoderamento, por exemplo, quando feministas obtiveram sucesso no curso de três décadas em estabelecer abuso sexual como um fato. Entretanto, apesar dos efeitos de enfraquecimento e empoderamento, a seleção por si mesma não afeta ou abala a

\footnotetext{
${ }^{24}$ ARENDT, Hannah. The Life of the Mind. pp. 53-65.

${ }^{25} \mathrm{Em}$ Arendt, senso comum é intimamente relacionado com ter o mundo em comum. Ela, até certo ponto, chamou senso comum de Weltsinn, sentido do mundo, conforme citado em BORREN, Amor Mundi. p. 119.

${ }^{26}$ ARENDT, Hannah. Between Past and Future. p. 238.
} 
verdade dos fatos. Apenas quando a seleção se torna manipulação, por exemplo, quando a informação factual é forjada, inventada ou retida, a verdade dos fatos é afetada.

Em termos hermenêuticos, seleção envolve interpretação, seja compreensão preliminar implícita ou compreensão reflexiva. Portanto, a verdade de um fato não pode ser estabelecida sem trazer perspectivas interpretativas. Isto se torna aparente especialmente na denominação de um evento selecionado ou sequência de eventos. O mesmo ato de violência pode ser nomeado e descrito como ato terrorista ou como ato de lutadores pela liberdade resistindo à ocupação de seu país. O mesmo ato sexual pode ser nomeado e descrito como sexo consensual ou estupro. Esses são fortes exemplos do impacto que as perspectivas interpretativas causam, entretanto, ao mesmo tempo, mostram também que ainda é possível distinguir verdade factual e interpretação. Tão logo seja possível estabelecer que ambos os nomes ou descrições têm a mesma referência - e os parâmetros comuns supracitados ajudam a estabelecer isso -, torna-se manifesto que ambas as nomeações das partes trazem perspectivas interpretativas diferentes para dar conta do mesmo evento.

A inseparabilidade entre fato e interpretação é também relevante em vista da novidade dos fatos. Arendt sabia muito bem que nada é mais difícil e mais contestado do que a tentativa de estabelecer novos fatos. A razão é óbvia. Em contraste com os fatos previsíveis que não desafiam o senso comum e os quadros estabelecidos de compreensão, novos fatos desafiam a compreensão de tal modo que temos dificuldades para reconhecê-los. Novos fatos parecem mais interpretação do que verdade porque o estabelecimento deles depende crucialmente do trabalho da interpretação reflexiva que tenta articular e compreender algo novo sem reduzi-lo a algo velho e conhecido. Um bom exemplo de tentativa de estabelecer um novo fato é a tese de Arendt sobre a banalidade do mal exemplificada pela pessoa de Eichmann. Questionando a visão simplista de que maus atos só podem ser cometidos por pessoas ruins, pessoas com maus motivos ou intenções más, Arendt tenta convencer os leitores de sua reportagem sobre o julgamento de Eichmann em Jerusalém que ele exemplifica um estado de coisas muito diferente. Aqui nós temos uma pessoa cuja responsabilidade pela morte de milhões não é devida a maus motivos como antissemitismo, mas à banalidade, isto é, à uma ausência de imaginação e reflexão, ou para dizer nas palavras de Arendt, ausência de pensamento [thoughtlessness]. A novidade do fato que Arendt tenta estabelecer não pertence tanto à pessoa do criminoso que, afinal de contas, era um servo civil bastante comum, assim como os tipos de crimes e os tipos de circunstâncias políticas que criaram esses crimes. As fábricas de morte e o totalitarismo são chocantes novidades e fenômenos sem precedentes, é a mensagem de Arendt em Origens do Totalitarismo e Eichmann em Jerusalém: Um relato sobre a banalidade do mal. Assim como ainda há muita discussão sobre se Arendt está correta, é ainda muito cedo para dizer se sua tentativa de estabelecer esses novos fatos foi bem-sucedida. ${ }^{27}$

\section{Conclusão: o mundo comum}

A inseparabilidade do fato e a interpretação significa que o estabelecimento dos fatos, em princípio, é sempre aberto e contestável, porque envolve a introdução de parâmetros comuns que não são sólidos e perspectivas que estão sempre mudando com o tempo e que são plurais. Além disso, fatos cobrem um amplo espectro, variando dos mais rígidos aos mais male-

\footnotetext{
${ }^{27}$ Para uma discussão sobre seu livro a respeito de Eichmann, ver neste caso, ASHHEIM, Steven. Hannah Arendt in Jerusalem. Los Angeles: University of California Press, 2001.
} 
áveis, isto é, dos fatos que permitem uma clara distinção entre verdade e interpretação, aos que dependem crucialmente da interpretação.

Retornando aos problemas mencionados no início deste ensaio, a inseparabilidade do fato e interpretação tem criado duas inferências errôneas. De um lado, a inferência popular de que fatos, por exigirem interpretação são invenções e consequentemente a verdade factual não existe. Por outro lado, a inferência de que a inseparabilidade do fato e interpretação é inerentemente relativista e precisa ser rejeitada em favor da separação do fato e da interpretação, onde a primeira representa objetividade e verdade, e a segunda subjetividade e avaliação. A segunda inferência é baseada na incompreensão da natureza da objetividade e da interpretação, restaurando uma noção defasada de objetividade ou verdade absolutas. Na medida em que têm esta restauração em comum, os fundamentalismos do mundo atual parecem mais um fenômeno reativo do que um novo estado de coisas.

A falácia da primeira inferência é que ela traz a conclusão errada do reconhecimento correto da inseparabilidade do fato e da interpretação. Inseparabilidade não implica identidade e mesmidade [sameness]. Pelo contrário, verdade e sentido são analiticamente e fenomenologicamente distintos. A rejeição da distinção entre verdade e sentido é também politicamente autodestrutiva, pois acaba com a possibilidade de contestação efetiva da manipulação dos fatos ou das mentiras descaradas do mundo político. Por exemplo, expor as mentiras de Bush e Blair sobre a presença de armas de destruição em massa no Iraque requer a distinção entre verdade factual e interpretação a fim de argumentar o que é a verdade factual neste caso em particular e o que tem sido deturpado e mentido acerca disso. Em resumo, exatamente porque fato e interpretação são indissoluvelmente entrelaçados, fatos, em princípio, sempre permitem contestação onde a verdade cessa e onde a interpretação começa.

O reconhecimento do estatuto paradoxal dos fatos é de vital importância para a sobrevivência e manutenção do mundo como um espaço público comum. Contra a convicção enraizada da filosofia hermenêutica, e boa parte da filosofia política contemporânea, de que a qualidade-comum [commonness] do mundo público comum depende do consenso ou acordo, Arendt sustenta que esta qualidade depende das perspectivas plurais. O mundo público, efêmero e imaterial, constituído por ações plurais que resultam em novos eventos e estados de coisas, depende da articulação de perspectivas plurais para sua sobrevivência e consolidação. lluminando o mesmo teatro mundano de pontos de vista diferentes, e frequentemente conflitantes, a pluralidade torna a efêmera e frágil "teia de relações humanas" 28 em um mundo perceptivelmente existente e, nesse sentido, compartilhado e compartilhável. Enquanto a pluralidade precisa ceder espaço ao consenso em Habermas e Gadamer, a comunalidade completamente pluralista do mundo público compartilhado, em Arendt, não requer nem exige consenso. Sem representações plurais, a teia intangível perderia primeiro a sua qualidade de mundo comum compartilhável, depois sua significação, e, por fim, sua realidade. A pluralidade, igualmente agonística e associativa, na medida em que implica interação de perspectivas potencialmente conflitantes, permite um mundo comum que é plural em vez de homogêneo. Enquanto perspectivas plurais iluminam os fatos de todos os lados, consolidando, deste modo, um mundo público compartilhado, a perspectiva homogênea cega mais do que ilumina. Como um refletor na escuridão, que mostra um inflexível mundo preto e branco, sem qualquer tom de cor, sem qualquer nuance ou detalhe. Sem representações plurais, a teia intangível perderia primeiro a sua qualidade de mundo comum compartilhável, depois sua significação, e, por fim, sua realidade.

${ }^{28}$ ARENDT, Hannah. The Human Condition. p. 183. 
A perda de um mundo plural compartilhável é o começo da erosão do mundo factual que, por sua vez, é a base do nosso senso de realidade. Que esse estado de coisas possa ser compensado pela criação de ficções ideológicas (o terceiro Reich de Hitler e as tão faladas repúblicas socialistas democráticas da União Soviética) é uma lição valiosa da descrição de Arendt sobre o totalitarismo europeu.

\section{Referências bibliográficas}

ARENDT, Hannah. The Origins of Totalitarianism. New York: Harcourt, 1951.

ARENDT, Hannah. Eichmann in Jerusalem: A Report on the Banality of Evil. New York:Viking Press, 1963.

ARENDT, Hannah. Essays in Understanding 1930-1954. Edited by Jerome Kohn. New York: Harcourt, 1994.

ARENDT, Hannah. Ich will verstehen: Selbstauskünfte zu Leben und Werk. Edited by Ursula Lutz. München: Piper, 1996.

ARENDT, Hannah. The Human Condition. Chicago: University of Chicago Press, 1958.

ARENDT, Hannah. The Life of the Mind. Vol. I: Thinking. New York: Harcourt, 1971.

ARENDT, Hannah. Between Past and Future: Eight Exercises in Political Thought. New York: Penguin, 1966.

ASHHEIM, Steven. Hannah Arendt in Jerusalem. Los Angeles: University of California Press, 2001. BENHABIB, Seyla. The Reluctant Modernism of Hannah Arendt. London: Sage, 1996.

BORREN, Marieke. Amor Mundi: Hannah Arendt's political phenomenology of world. Disponible in: http://dare.uva.nl/record/346972.

CAPUTO, John D. Radical Hermeneutics. Repetition, Deconstruction, and the Hermeneutic Project. Bloomington: Indiana University Press, 1987.

FOUCAULT, Michel. Histoire de la sexualité. Vol. I : La volonté de savoir. Paris: Gallimard, 1976.

GADAMER, Hans-Georg. Truth and Method. $2^{\mathrm{a}}$ ed.Trans. byJoel Weinsheimere Donald G. Marshall. New York: Continuum, 1999.

TAMINIAUX, Jacques. La fille de Thrace et le penseur professional: Arendt et Heidegger. Paris: Éditions Payot, 1992.

VASTERLING, Veronica. Postmodern Hermeneutics? Toward a Critical Hermeneutics. In: CODE, Lorraine. (Ed.). Feminist Interpretations of Hans-Georg Gadamer. University Park Pa: Pennsylvania State University Press, 2003.

VASTERLING, Veronica. Hannah Arendt. In: LUFT, Sebastian; OVERGAARD, Søren. (Ed.). Routledge Companion to Phenomenology. London: Routledge, 2011.

Sobre o tradutor

José Valdir Teixeira Braga Filho

Graduado em Filosofia pela UECE e Mestrando em Filosofia pela UFC.

Recebido em: 20/01/2020

Aprovado em: 17/06/2020 